\title{
EFFICACY OF SIX-DOSE REGIMEN OF ARTEMETHER-LUMEFANTRINE FOR THE TREATMENT OF UNCOMPLICATED FALCIPARUM MALARIA, THREE YEARS AFTER ITS INTRODUCTION INTO ETHIOPIA
}

\author{
KEFYALEW T.*, ANIMUT A.*, TAMENE T.*, JIMA D.**, HAILEMARIAM A.** \& LEGESSE M.*
}

\section{Summary:}

We assessed the clinical and parasitological efficacy of six-dose regimen of artemether-lumefantrine (AL) (Coartem $\left.{ }^{\circledR}\right)$ for treating uncomplicated $P$. falciparum malaria three years after its introduction into Ethiopia. A total of 102 patients (mean age: 15.7 years; age range: 1-50 years) were enrolled in the study and followed-up for 28 days based on WHO protocol. Treatment with $\mathrm{AL}$ resulted in $100 \%$ adequate clinical and parasitological response (ACPR). No severe side-effect of the drug was observed. All patients had rapid clinical and parasitological responses. None of the subject was found to be positive for asexual or sexual stage of the parasite after day 3. A significant increase in the mean of haemoglobin level was observed on day 28 posttreatment $(11.4 \mathrm{~g} / \mathrm{dL}$ on day 0 vs $12.3 \mathrm{~g} / \mathrm{dL}$ on day 28 , $\mathrm{p}<0.05)$. Thus, artemisinin-based combination therapies (ACTs) seem to mitigate not only the problem of drug resistance malaria but also the transmission of the disease. Nevertheless, monitoring ACT therapeutic efficacy is crucial in Ethiopia.

KEY WORDS : P. falciparum, malaria, artemether-lumefantrine, efficacy, Ethiopia.

T n Ethiopia, malaria is a major public health problem. Plasmodium falciparum is the widely distributed species, which cause the majority of morbidity and mortality especially in malaria epidemic situations (UNICEF Ethiopia). Chloroquine (CQ) was the most common antimalarial drug used to treat falciparum malaria for decades in the country. However, the wide spreads of multi-drug resistant $P$. falciparum incapacitated the use of CQ (Taklehaimanot, 1986) and then sulphadoxine-pyrimethamine (SP) (Jima et al., 2005) as in many African countries (Trape, 2001; Korenromp et al., 2003; Winstanley et al., 2004).

As a response to increasing levels of resistance to antimalarial drugs, WHO (2001) recommends that all countries experiencing resistance to conventional mono-

\footnotetext{
* Aklilu Lemma Institute of Pathobiology, Addis Ababa University, P.O.B. 1176, Ethiopia.

** Federal Ministry of Health, Malaria and other vector Borne Diseases Control Unit, Ethiopia.

Correspondence: Mengistu Legesse

Fax: 0025-11-275-5296 - E-mail: dlegessem@yahoo.com
}

Résumé : EFFicaCité Clinique et PARASITOLOGIQUe de l'ASSOCIATION ARTHÉMÉTHER-LUMÉFANTRINE EN SIX PRISES SUR LE PALUDISME NON COMPLIQUÉ À P. FALCIPARUM, TROIS ANS APRÈS SA MISE À DISPOSITION EN ÉTHIOPIE

Nous avons estimé l'efficacité clinique et parasitologique de I'association arthéméther-luméfantrine (AL) (Coartem $\left.{ }^{\circledR}\right)$ en six prises sur le paludisme non compliqué à P. falciparum, trois ans après sa mise à disposition en Ethiopie. 102 patients d'âge moyen de 15,7 ans (1-50 ans) ont été inclus dans l'étude et suivis pendant 28 jours selon le protocole de l'OMS. Une bonne réponse clinique et parasitologique a été observée chez $100 \%$ des sujets traités par AL. Aucun effet secondaire sévère n'a été relevé. Les reponses clinique et parasitologiques ont été rapides chez tous les patients. Après trois jour de traitement, aucun d'entre eux ne présentait de parasite à un stade sexué ou asexué. Une élévation significative de l'hémoglobinémie à été observée au $28^{\mathrm{ème}}$ jour de tritement (1 1,4 g/dL à J-O vs 12,3 g/dL à J-28, $p<0,05)$. Si les traitements combinés à base d'artémisinine semblent atténuer les problèmes de résitance de $\mathrm{P}$. falciparum aux antipaludéens, ils diminuent aussi la transmission de la maladie. Pour autant, le suivi de l'efficacité de ces traitements combinés est d'une importance capitale en Éthiopie.

MOTS CLÉS : P. falciparum, paludisme, arthéméther-luméfantrine, efficacité, Éthiopie.

therapies, such as CQ, AQ or sulfadoxine-pyrimethamine (SP), should use combination therapies, preferably those containing artemisinin derivatives (ACTs - artemisinin-based combination therapies) for treatment of uncomplicated falciparum malaria. In line with this WHO guideline, Ethiopia has also decided to use artemether-lumefantrine (AL) as the first-line drug for the treatment of uncomplicated falciparum malaria since July 2004 (FMOH, 2004). The safety and therapeutic efficacy of six-dose regimen of AL against $P$. falciparum was studied at it's introduction in limited malaria endemic sites and reported to be $99.1 \%$ efficacious (Jima et al., 2005b). Nevertheless, experience from previous unexpected resistance development of falciparum malaria parasite to effective antimalarial drugs necessitates substantial re-assessment of the efficacy of AL against $P$. falciparum to monitor efficacy on regular basis for possible emergence of resistance and ensuring a continued coverage of effective treatment (Hasting et al., 2007). In this study, the current clinical and parasitological efficacy of six-dose regimen of $\mathrm{AL}$ 
was assessed for the treatment of uncomplicated falciparum malaria three years after its introduction into Ethiopia.

\section{PATIENTS AND METHODS}

\section{STUDY SITE AND PERIOD}

T The study was conducted at Alaba Kulito Health Center, Southern Ethiopia between October and December 2007. Alaba Kulito Health Center is found in a rural town about $313 \mathrm{~km}$ to the south of Addis Ababa. Most of the inhabitants were belonged to Alaba ethnic group and earn their living as farmers practicing settled mixed agriculture, mainly cultivation of maize and rearing of cattle. Alaba area experiences dry winter and rainy summer seasons. It's annual temperature and rainfall ranges between $18-23^{\circ} \mathrm{C}$ and 857 $1,085 \mathrm{~mm}$, respectively. The area is located at an altitude ranges from 1,700 to 2,200 meter above sea level. The area is endemic for malaria and the transmission is seasonal. Malaria transmission occurs from August to December following the major rainy season while minor transmission occurs in April and May. P. falciparum and $P$. vivax are prevalent in the area. The area is characterized by low to moderate malaria transmission intensity. The study site was purposely selected; because it is an area where a treatment failure rate of SP to P. falciparum was recorded in 2003 (Jima et al., 2005a), and AL has been used as the first-line drug for the treatment of uncomplicated falciparum malaria since its implementation in the country (FMOH, 2004).

\section{PATIENT ENROLMENT}

All self presented patients age over one year and suspected for malaria were eligible to be screened for recruitment in the study. WHO guideline for the in vivo assessment of the therapeutic efficacy of anti-malarial drugs in the treatment of uncomplicated falciparum malaria was used to estimate sample size and enrolled the patients (WHO, 2003). Accordingly, the inclusion criteria were mono-infection with $P$. falciparum, parasitaemia between 1,000 and $100,000 / \mu$ l of blood, axillary temperature $\geq 37.5^{\circ} \mathrm{C}$ or a history of fever during the last 24 hours, body weight $>10 \mathrm{~kg}$, absence of severe malnutrition, absence of febrile conditions caused by diseases other than malaria, absence of signs of severe malaria, haemoglobin $(\mathrm{Hb}) \geq 5 \mathrm{~g} / \mathrm{dl}$, able to come during the stipulated schedule and informed consent of parents/ guardians.

\section{TREATMENT AND FOLLOW-UP}

Patients were treated with six-dose regimen of $\mathrm{AL}$ (Coartem $^{\circledR}$; Novartis Pharma AG, Basel, Switzerland) according to body weight as per the national malaria diagnosis and treatment guideline (FMOH, 2004). The patients were directly observed for at least 30 minutes following the first dose administration. For those who vomited within 30 minutes of treatment, the full treatment dose was repeated. All patients took the morning doses under direct supervision for the three consecutive days, while the evening doses were given to the patients or their guardians to be taken at home with adequate instruction. Next morning, the patients or their guardians were interviewed for proper use of the drug and absence of vomiting. Paracetamol tablets were given to some of the patients who were complaining for high fever.

Patients were regularly re-assessed on days 1, 2, 3, 7, 14, 21 and 28 and any other day when he/she reported unwell. Blood was obtained by finger prick on days 0, 3, 7, 14, 21 and 28. Thick and thin blood films were prepared, stained with $10 \%$ Giemsa for 10 minutes and microscopically examined for malaria parasites. Parasite count was performed by counting the number of asexual parasites per 200 white blood cells, and parasite density was calculated per micro liter of blood

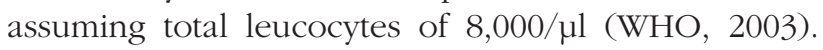
Blood films were considered negative if no asexual forms of $P$. falciparum were observed thick in 100 film fields. Species were confirmed on the fixed thin smear. Gametocytes were also scanned and counted during the follow-up period.

Blood samples were also collected on day 0 on to filter paper for molecular analysis in case of parasite reappearance during the follow-up period. Haemoglobin was measured on day 0 and day 28 using a HemoCue portable photometer. Relevant clinical signs and symptoms as well as body temperature of all the study subjects were assessed and recorded by experienced health officers on day 0 and during the follow up periods.

\section{ASSESSMENT OF TREATMENT OUTCOME}

Early Treatment Failure (ETF), Late Clinical Failure (LCF), Late Parasitological Failure (LPF) and Adequate Clinical and Parasitological Response (ACPR) were assessed as outcomes using WHO guideline for the in vivo assessment of the therapeutic efficacy of anti-malarial drugs in the treatment of uncomplicated falciparum malaria (WHO, 2003).

\section{STATISTICAL ANALYSIS}

Data were entered and analyzed using a software designed by WHO for therapeutic efficacy assessment (http://www.who.int/malaria/toolsformonitoring.html). Efficacy data was analyzed for patients who completed the follow-up. Variables ETF, LCF, LPF, ACPR, asexual and sexual stages, average body temperature, haemoglobin level and clinical sign and symptoms 
were summarized using tables and figures when appropriate. Changes in average parasiteamia and gametocyte levels between day 0 and day 3 , and changes in average haemoglobin level between day 0 and day 28 were compared using paired t-test and $\mathrm{Khi}^{2}$ test was used to compare proportion. $P$ value less than 0.05 was considered statistically significant.

\section{ETHICAL CONSIDERATIONS}

The study protocol was reviewed and approved by the Ethics Committee of the Aklilu Lemma Institute of Pathobiology, Addis Ababa University as well as by the National Ethical Clearance Committee. Written informed consent was obtained from participants or guardians. Blood samples were collected under aseptic conditions. Patients who were not included in the study, but found positive either for $P$. falciparum or $P$. vivax malaria were treated according to the national policy for malaria treatment in Ethiopia (FMOH, 2004).

\section{RESULTS}

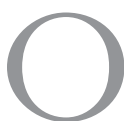

f 2,000 self presenting febrile patients screened for malaria, 190 (9.5\%), 1,048 (52.4\%) and 7 $(0.35 \%)$ were infected with $P$. falciparum,

\begin{tabular}{|c|c|}
\hline Characteristic & Value \\
\hline \multicolumn{2}{|l|}{ No. of patients } \\
\hline$<5$ years & $15(14.7 \%)$ \\
\hline $5-15$ years & $38(37.3 \%)$ \\
\hline$>15$ years & $49(48.0 \%)$ \\
\hline Mean age (years) & $\begin{array}{c}15.7 \\
\text { (range : 1-50) }\end{array}$ \\
\hline Mean body weight $(\mathrm{kg})$ & $\begin{array}{c}35.8 \\
\text { (range }: 9.7-78.5 \text { ) }\end{array}$ \\
\hline Average body temperature $\left({ }^{\circ} \mathrm{C}\right)$ & $\begin{array}{c}37.5 \\
\text { (range : } 35.5-40)\end{array}$ \\
\hline Mean haemoglobin $(\mathrm{g} / \mathrm{dL})$ & $\begin{array}{c}11.4 \\
\text { (range : } 5-17.1 \text { ) }\end{array}$ \\
\hline Mean parasitaemia (count $/ \mu$ l of blood) & $\begin{array}{c}8,264.3 \\
\text { (range : } 1,000-88,000)\end{array}$ \\
\hline Mean gametocytaemia (count/ $\mu$ l of blood) & $\begin{array}{c}0.3 \\
{\text { (range } 0-14)^{\mathrm{c}}}^{\mathrm{c}}\end{array}$ \\
\hline
\end{tabular}

Table I. - Baseline characteristics on day 0 of the 102 patients who completed the follow-up.
$P$. vivax and with $P$. falciparum plus $P$. vivax respectively. Among falciparum malaria cases, 108 (56.8 \%) fulfilled the inclusion criteria and enrolled in the study. Six patients $(5.6 \%)$ were excluded from the analysis (five cases were lost to follow-up and one individual took additional anti-malarial medication from private pharmacy during the follow-up period). Of the 102 patients who completed the follow-up, 97 (95.1\%) had asexual stage and $5(4.9 \%)$ had both asexual and sexual (gametocytes) stages. The baseline characteristics of participants are shown in Table I.

Table II shows level of parasitaemia, gametocytes and body temperature during the follow up period. High parasitaemia reduction rate was observed on day 3 compared to day $0(8,264.3$ vs $8.6, \mathrm{p}<0.000)$. None of the subject was found positive for asexual parasitaemia or gametocytes after day 3 and thereafter. Haemoglobin level also showed progressive increment from an average of $11.4 \mathrm{~g} / \mathrm{dL}$ on day 0 to $12.3 \mathrm{~g} / \mathrm{dL}$ on day 28 ( $\mathrm{p}<0.05)$.

Of 102 patients who completed the follow-up, $100 \%$ were assessed as ACPR, and there was no treatment failure (Table III).

$\left.\begin{array}{ccc}\hline \text { Treatment outcomes } & \begin{array}{c}\text { Number } \\ \text { of patients }\end{array} & \text { Percentage } \\ \hline \text { ETF } & 0 & \left.\begin{array}{c}0 \% \\ 95 \% \text { CI: } 0-3.5 \%) \\ 0 \%\end{array}\right) \\ \text { LCF } & 0 & \left(\begin{array}{c}95 \% \text { CI: } 0-3.5 \%) \\ 0 \%\end{array}\right) \\ \text { LPF } & 0 & (95 \% \text { CI: } 0-3.5 \%) \\ 100 \%\end{array}\right)$

Table III. - Parasitological and clinical responses of patients with uncomplicated $P$. falciparum malaria following treatment with Coartem $^{\circledR}$.

On day of admission, 96 (94.1\%), 82 (80.4\%), 74 (72.5\%), 78 (76.5\%), 34 (33.3\%), 21 (20.6\%), 19 $(18.6 \%)$ and $4(3.9 \%)$ subjects had complained fever, weakness, muscle pain, headache, anorexia, cough, vomiting and diarrhea respectively. Most of these cli-

\begin{tabular}{|c|c|c|c|c|c|c|}
\hline Description & $\begin{array}{c}\text { Day 0 } \\
\text { Mean (SD) }\end{array}$ & $\begin{array}{c}\text { Day } 3 \\
\text { Mean (SD) }\end{array}$ & $\begin{array}{c}\text { Day } 7 \\
\text { Mean (SD) }\end{array}$ & $\begin{array}{c}\text { Day } 14 \\
\text { Mean (SD) }\end{array}$ & $\begin{array}{c}\text { Day } 21 \\
\text { Mean (SD) }\end{array}$ & $\begin{array}{c}\text { Day } 28 \\
\text { Mean (SD) }\end{array}$ \\
\hline Trophozoites/ul of blood & $8,264.3(12,620.6)$ & $8.6(54.8)$ & 0 & 0 & 0 & 0 \\
\hline Gametocytes/ $\mu$ l of blood & $0.3(1.6)$ & $0.1(0.8)$ & 0 & 0 & 0 & 0 \\
\hline Haemoglobin $(\mathrm{g} / \mathrm{dL})$ & $11.4(2.8)$ & NM & NM & NM & NM & $12.3(2.3)$ \\
\hline Average body Tem $\left({ }^{\circ} \mathrm{C}\right)$. & $37.5(0.8)$ & $36.8(0.6)$ & $36.6(0.6)$ & $36.4(0.7)$ & $36.6(0.5)$ & $36.7(0.5)$ \\
\hline
\end{tabular}

$\mathrm{NM}=$ not measured.

Table II. - Levels of parasitaemia, sexual stage and average body temperature of the participants on admission and during the follow up period. 


\begin{tabular}{|c|c|c|c|c|c|c|c|c|}
\hline \multirow[b]{2}{*}{ Symptoms } & \multicolumn{8}{|c|}{ Follow-up days and number of complaints (\%) } \\
\hline & Day 0 & Day 1 & Day 2 & Day 3 & Day 7 & Day 14 & Day 21 & Day 28 \\
\hline \multirow[t]{2}{*}{ Fever } & 96 & 57 & 18 & 7 & 2 & 0 & 0 & 1 \\
\hline & $(94.1 \%)$ & $(55.9 \%)$ & $(17.6 \%)$ & $(6.9 \%)$ & $(2.0 \%)$ & $(0 \%)$ & $0(0 \%)$ & $(0.98 \%)$ \\
\hline \multirow[t]{2}{*}{ Weakness } & 82 & 61 & 21 & 11 & 7 & 6 & 1 & 0 \\
\hline & (80.4\%) & $(59.8 \%)$ & (20.6\%) & (10.8\%) & (6.9 \%) & (5.9\%) & $(0.98 \%)$ & $(0 \%)$ \\
\hline \multirow[t]{2}{*}{ Headache } & 78 & 35 & 10 & 6 & 4 & 6 & 0 & 1 \\
\hline & $(76.5 \%)$ & $(34.3 \%)$ & $(9.8 \%)$ & $(5.9 \%)$ & $(3.9 \%)$ & $(5.9 \%)$ & $(0 \%)$ & $(0.98 \%)$ \\
\hline \multirow[t]{2}{*}{ Muscle pain } & 74 & 44 & 11 & 6 & 2 & 5 & 2 & 1 \\
\hline & $(72.5 \%)$ & $(43.1 \%)$ & (10.8\%) & $(5.9 \%)$ & $(2.0 \%)$ & $(4.9 \%)$ & $(2.0 \%)$ & $(0.98 \%)$ \\
\hline \multirow[t]{2}{*}{ Anorexia } & 34 & 11 & 3 & 0 & 1 & 0 & 0 & 0 \\
\hline & $(33.3 \%)$ & $(10.8 \%)$ & $(2.9 \%)$ & $(0 \%)$ & $(0.98 \%)$ & $(0 \%)$ & $(0 \%)$ & $(0 \%)$ \\
\hline \multirow[t]{2}{*}{ Cough } & 21 & 14 & 10 & 4 & 2 & 2 & 2 & 0 \\
\hline & (20.6\%) & $(13.7 \%)$ & (9.8 \%) & (3.9\%) & $(2.0 \%)$ & $(2.0 \%)$ & (2.0\%) & $(0 \%)$ \\
\hline \multirow[t]{2}{*}{ Vomiting } & 19 & 1 & 0 & 0 & 0 & 0 & 0 & 0 \\
\hline & (18.6\%) & $(0.98 \%)$ & $(0 \%)$ & $(0 \%)$ & $(0 \%)$ & $(0 \%)$ & $(0 \%)$ & $(0 \%)$ \\
\hline \multirow[t]{2}{*}{ Diarrhea } & 4 & 2 & 2 & 0 & 1 & 0 & 1 & 0 \\
\hline & $(3.9 \%)$ & $(2.0 \%)$ & $(2.0 \%)$ & $(0 \%)$ & $(0.98 \%)$ & $(0 \%)$ & $(0.98 \%)$ & $(0 \%)$ \\
\hline
\end{tabular}

Table IV. - Patients clinical complain on admission and during the follow up period.

nical symptoms were resolved by day $3(\mathrm{p}<0.05)$, and few patients complained up to day 28 (Table IV). Any severe adverse effect of the drug was not reported/observed during the follow-up.

\section{DISCUSSION}

I $\mathrm{n}$ this study, we carried out efficacy study on AL three years after its implementation in an area where a treatment failure of SP to $P$. falciparum was previously documented (Jima et al., 2005a). Series evidences have shown high efficacy of ACTs against $P$. falciparum even in multidrug-resistant strains of the parasite (Lefevre et al., 2001; Makanga et al., 2006; Adama et al., 2007; Menard et al., 2008; Kaddouri et al., 2008). Nevertheless, substantial re-assessment of the efficacy of this combination therapy against $P$. falciparum is crucial to monitor possible emergence of resistance and ensuring a continued coverage of effective treatment.

Our results showed $100 \%$ ACPR to AL. This is comparable with the previous study that showed a high treatment success rate $(99.1 \%)$ in the country (Jima et al., 2005b). The finding of this study is also in agreement with other studies in children and adults elsewhere using ACTs (Van Vugt et al., 1999, 2000; Lefevre et al., 2001; Flade et al., 2005; Jima et al., 2005b; Piola et al., 2005; Piola et al., 2005; Guthmann et al., 2006; Van den Broek et al., 2006; Adama et al., 2007).

In a study conducted in Senegal, the efficacy of AL was found to be $100 \%$ when given as six doses, while it was found to be reduced by $3.6 \%$ when given as four doses (Faye et al., 2007). Study by Lefevre et al. (2001) showed a high efficacy and safety of six-dose of AL when administrated as four tablets twice daily for three consecutive days. Moreover, a pooled analysis of individual patient data confirmed higher efficacy of six-dose regimen of AL compared to four-dose regimen in children (Makanga et al., 2006). The present result also indicated the importance of maintaining the sixdose regimen for the treatment of uncomplicated falciparum malaria with regularly monitoring for its effectiveness especially in areas where multi-drug resistance falciparum malaria is common (Hastings et al., 2007). In this study, treatment with $\mathrm{AL}$ was also found to induce rapid clearance of malaria symptoms which is in agreement with previously conducted study in Ethiopia and clinical studies conducted elsewhere using ACTs (Bakshi et al., 2000; Lefevre et al., 2001; Jima et al., 2005b; Mulenga et al., 2006; Menard et al., 2008). In addition to its rapid parasitological and malaria symptoms clearance, AL showed high gametocyte reduction during the follow-up. This observation supports the implication that artemisinin-based combination therapy could have additional benefit to the community by reducing falciparum malaria transmission if the drug is widely deployed in endemic areas (Targett et al., 2001; Guthmann et al., 2006; Van den Broek et al., 2006; Mulenga et al., 2006; Hatz et al., 2008). Compared to baseline data, a significant increase in the mean of haemoglobin level was observed on day 28 post-treatment, which also indicates the added benefit of treating patients with this combination therapy as anemia could be aggravated by resistant parasite (Guthmann et al., 2006; Van den Broek et al., 2006; Mulenga et al., 2006).

\section{CONCLUSION}

A L was found to be highly efficacious for the treatment of falciparum malaria three years after its introduction in Ethiopia without serious 
adverse events. In addition, the drug has shown a gametocytocidal effect. Thus, ACTs seem to mitigate not only the problem of drug resistance malaria but also the transmission of the disease. Nevertheless, there is a need to assess periodically the therapeutic efficacy of AL in Ethiopia, as part of the activities for the surveillance of the emergence of resistant parasite against this valuable drugs.

\section{ACKNOWLEDGEMENTS}

The authors would like to thank the study participants and the staff of Alaba Kulito Health Center for their cooperation. The study was financially supported by Federal Ministry of Health of Ethiopia. We would also like to acknowledge Miss Kokobe GebreMichael, technical staff of Aklilu Lemma Institute of Pathobiology, Addis Ababa University, for her technical assistance.

\section{REFERENCES}

Adama T., Leon R., Vincent R., Ahmed B.S., Frederic A. \& MiliJAONA R. Efficacy of artesunate plus amodiaquine, artesunate plus sulfadoxine-pyrimethamine, and chloroquine plus sulfadoxine-pyrimethamine in patients with uncomplicated Plasmodium falciparum in the Comoros Union. Acta Tropica, 2007, 102, 176-181.

Bakshi R., Hermeling-Fritz I., Gathmann I. \& Alteri E. An integrated assessment of the clinical safety of artemether-lumefantrine: a new oral fixed-dose combination antimalarial drug. Transaction of the Royal Society of Tropical Medicine and Hygiene, 2000, 94, 419-924.

Falade C., Makanga M., Premji Z., Ortmann C.E., Stockmeyer M. \& DE Palacios P.I. Efficacy and safety of artemether-lumefantrine $\left(\right.$ Coartem ${ }^{\circledR}$ ) tablets (six-dose regimen) in African infants and children with acute, uncomplicated falciparum malaria. Transaction of the Royal Society of Tropical Medicine and Hygiene, 2005, 99, 459-467.

Faye B., Ndiaye J.L., Ndiaye D., Dieng Y., Faye O. \& Gaye O. Efficacy and tolerability of four antimalarial combinations in the treatment of uncomplicated Plasmodium falciparum malaria in Senegal. Malaria Journal, 2007, 6, 80-89.

Federal Ministry of Health. Malaria diagnosis and treatment guidelines for health workers in Ethiopia, Malaria and other vector borne diseases control unit. Diseases prevention and control department, $2^{\text {nd }}$ edition. Addis Ababa, Ethiopia, 2004 .

Guthmann J.P., Cohuet S., Rigutto C., Fortes F., Saraiva N., Kiguli J., Kyomuhendo J., Francis M., Noel F., Mulemba M. \& BALKAN S. High efficacy of two artemisinin-based combinations (artesunate + amodiaquine and artemether + lumefantrine) in Caala, Central Angola. American Journal of Tropical Medicine and Hygiene, 2006, 75, 143-145.

Hastings I.M., Korenromp E.L. \& Bloland P.B. The anatomy of a malaria disaster: drug policy choice and mortality in
African children. Lancet Infectious Diseases, 2007, 7, 739748.

Hatz C., Soto J., Nothdurft H.D., Zoller T., Weitzel T., Loutan L., Bricaire F., Gay F., Burchard G.D., Andriano K., Lefevre G., De Palacios P.I. \& Genton B. Treatment of acute uncomplicated falciparum malaria with artemether-lumefantrine in nonimmune populations: a safety, efficacy, and pharmacokinetic study. American Journal of Tropical Medicine and Hygiene, 2008, 78, 241-247.

Jima D., Tesfaye G., Medhin A., Kebede A., Argaw D. \& BabaNIYI O. Efficacy of sulfadoxine-pyrimethamine for the treatment of uncomplicated falciparum malaria in Ethiopia. East African Medical Journal, 2005a, 82, 391-395.

Jima D., Tesfaye G., Medhin A., Kebede A., Argaw D. \& BabaNIYI O. Safety and efficacy of artemether-lumefantrine in the treatement of uncomplicated falciparum malaria in Ethiopia. East African Medical Journal, 2005b, 82, 387-390.

Kaddouri H., Djimde A., Dama S., Kodio A., Tekete M., Hubert V., Kone A., Maiga H., Yattara O., Fofana B., Sidibe B., Sangare C.P., Doumbo O. \& Le Bras J. Baseeline in vitro efficacy of ACT component drugs on Plasmodium falciparum clinical isolates from Mali. International Journal of Parasitology, 2008, 38, 791-798.

Korenromp E.L., Williams B.G., Gouws E., Dye C. \& Snow R.W. Measurement of trends in childhood malaria mortality in Africa: an assessment of progress toward targets based on verbal autopsy. Lancet Infectious Diseases, 2003, 3, 349-358.

Lefevre G., Looareesuwan S., Treeprasertsuk S., Krudsood S., Silachamroon U., Gathmann I., Mull R. \& Bakshi R. A clinical and pharmacokinetic trial of six doses of artemetherlumefantrine for multidrug-resistant Plasmodium falciparum malaria in Thailand. American Journal of Tropical Medicine and Hygiene, 2001, 64, 247-256.

Makanga M., Premji Z., Falade C., Karbwang J., Mueller E., Andriano K., Hunt P. \& Ibarra D.P. Efficacy and safety of the six-dose regimen of artemether-lumefantrine in pediatrics with uncomplicated Plasmodium falciparum malaria: A pooled analysis of individual patient data. American Journal of Tropical Medicine and Hygiene, 2006, 74, 991998.

Menard D., Ratsimbasoa A., Randrianarivelojosia M., Rabarijaona L.P., Raharimalala L., Domarle O., Randrianasolo L., Randriamanantena A., Jahevitra M., Andriantsoanirina V., Rason M.A., Raherinjafy R., RaKotomalala E., Tuseo L. \& RAVELOSON A. Assessment of the efficacy of antimalarial drugs recommended by the National Malaria Control Programme in Madagascar: up-dated baseline data from randomised and multi-site clinical trials. Malaria Journal, 2008, 7, 55-66.

Mulenga M., Van geertruyden J.P., Mwananyanda L., Chalwe V., Moerman F., Chilengi R., Van Overmeir C., Dujardin J.C. \& D'AlessandRo U. Safety and efficacy of lumefantrine-artemether $\left(\right.$ Coartem $\left.^{\circledR}\right)$ for the treatment of uncomplicated Plasmodium falciparum malaria in Zambian adults. Malaria Journal, 2006, 5, 73-80.

Piola P., Fogg C., Bajunirwe F., Biraro S., Grandesso F., Ruzagira E., Babigumira J., Kigozi I., Kiguli J., Kyomuhendo J., Ferradini L., Taylor W., Checchi F. \& Guthmann JP. Super- 
vised versus unsupervised intake of six-dose artemetherlumefantrine for treatment of acute, uncomplicated Plasmodium falciparum malaria in Mbarara, Uganda: a randomised trial. Lancet, 2005, 365, 14671473.

Targett G., Drakeley C., Jawara M., von Seidlein L., ColeMAN R., DEEN J. et al. Artesunate reduces but does not prevent post treatement transmission of Plasmodium falciparum to Anopheles gambiae. Journal of Infectious Diseases, 2001, 183, 1254-1259.

Teklehaimanot A. Chloroquine resistant $P$. falcparium in Ethiopia. Lancet, 1986, 2, 127-129.

TrAPE J.F. The public health impact of chloroquine resistance in Africa. American Journal of Tropical Medicine and Hygiene, 2001, 64 (1-2 Suppl.), 12-17.

UNICEF Ethiopia-Malaria (http://www.unicef.org/ethiopia/ malaria.html)

Van den Broek I., Kitz C., Al Attas S., Libama F., BalasegaRAM M. \& GUTHMANN J.P. Efficacy of three artemisinin combination therapies for the treatment of uncomplicated Plasmodium falciparum malaria in the Republic of Congo. Malaria Journal, 2006, 5, 113-122.

Van Vugt M., Looareesuwan S., Wilairatana P., McGready R., Villegas L., Gathmann I., Mull R., Brockman A., White N.J. \& Nosten F. Artemether-lumefantrine for the treatment of multidrug-resistant falciparum malaria. Transaction of the Royal Society of Tropical Medicine and Hygiene, 2000, 94, 545-548.

Van Vugt M., Wilairatana P., Gemperli B., Gathmann I., Phaipun L., Brockman A., Luxemburger C., White N.J., Nosten F. \& LoOAREESUwAN S. Efficacy of six doses of artemetherlumefantrine (benflumetol) in multidrug-resistant Plasmodium falciparum malaria. American Journal of Tropical Medicine and Hygiene, 1999, 60, 936-942.

Winstanley P., Ward S., SNOw R. \& BRECKEnRidge A. Therapy of falciparum malaria in sub-saharan Africa: from molecule to policy. Clinical Microbiology Review, 2004, 17, 612637.

World Health Organization. Antimalarial drug combination therapy: Report of WHO technical consultation. Geneva, April 2001.

World Health Organization. Assessment and monitoring of antimalarial drug efficacy for the treatment of uncomplicated falciparum malaria. Geneva, 2003.

Reçu le 20 octobre 2008 Accepté le 3 décembre 2008 